\title{
Serum lipid profile and correlates in newly presenting Nigerians with arterial hypertension
}

\author{
This article was published in the following Dove Press journal: \\ Vascular Health and Risk Management \\ 2 December 2013 \\ Number of times this article has been viewed
}

\author{
Umar G Adamu' \\ George A Okuku² \\ Clement O Oladele' \\ Aisha Abdullahi ${ }^{3}$ \\ Joanah I Oduh' \\ Abidemi J Fasae ${ }^{4}$ \\ 'Department of Medicine, \\ ${ }^{2}$ Department of Haematology, \\ Federal Medical Centre, Bida, \\ Niger State, ${ }^{3}$ Department of Nursing \\ Services, General Hospital, Minna, \\ Niger State, ${ }^{4}$ Department of Medicine, \\ Federal Medical Centre, Ido-Ekiti, \\ Ekiti State, Nigeria
}

Background: Arterial hypertension and dyslipidemia are modifiable cardiovascular risk factors. The multiplicative effect of these risk factors may worsen the atherogenic index of an individual. The objective of this study was to determine the pattern and prevalence of dyslipidemia in newly presenting Nigerians with arterial hypertension, as well as determine some of its correlates.

Methods: This cross-sectional study compared 115 newly presenting, age- and sex-matched individuals with arterial hypertension with 115 normotensive individuals. Fasting lipids, total cholesterol (TC), triglycerides, high-density lipoprotein cholesterol (HDL-C), low-density lipoprotein cholesterol (LDL-C), and fasting plasma glucose were estimated.

Results: Patients with arterial hypertension had higher body mass index ( $t=7.64 ; P=0.000)$, TC $(t=2.95 ; P=0.006)$, and HDL-C $(t=-5.18 ; P=0.000)$. The most common dyslipidemia was low HDL$\mathrm{C}$, found in both the hypertensive $(44.3 \%)$ and normotensive $(20.9 \%)$ patients. The prevalence of dyslipidemia in hypertensives and controls was $64 \%$ and $39 \%$, respectively. In hypertensive patients, TC correlated positively to diastolic blood pressure $(r=0.218 ; P=0.0019)$. Other positive correlates include LDL-C and age $(r=0.217 ; P=0.020)$ and fasting plasma glucose $(r=0.202 ; P=0.030)$ and body mass index $(r=0.209 ; P=0.025)$. Among normotensive controls, TC correlated positively with LDL-C ( $r=0.63 ; P=0.000)$ but correlated negatively with triglycerides $(r=-0.30 ; P=0.001)$.

Conclusion: Lipid abnormalities are common in newly presenting Nigerians with arterial hypertension. Screening of these risk factors, promotion of healthy lifestyle, and the institution of therapy is desirable to reduce their multiplicative effects.

Keywords: healthy lifestyle, screening, high-density lipoprotein cholesterol, cardiovascular, atherogenic index

\section{Introduction}

Hypertension is an important public health problem in developing countries and a major cause of morbidity and mortality. ${ }^{1}$ Studies have consistently indicated that hypertension and hypercholesterolemia frequently coexist, a term known as dyslipidemic hypertension..$^{2-4}$

The Framingham Heart Study data on the hypertensive population reported that more than $80 \%$ had at least one additional cardiovascular disease risk factor, and that predominantly these risk factors were atherogenic in nature. ${ }^{3}$ Dyslipidemic hypertension constitutes the important components of the metabolic syndrome, as defined by the National Cholesterol Education Program Guidelines (Adult Treatment Panel III). ${ }^{5}$ The risk of cardiovascular diseases associated with hypertension coexisting with dyslipidemia is more multiplicative than the sum of the individual risk factors. ${ }^{6-9}$
Correspondence: Umar G Adamu Department of Medicine, Federal Medical Centre, Efu Etsu yisa, PMB 14, Bida Niger State, Nigeria Tel +2347030483770 Email ugadamu@yahoo.com 
In a national survey by Akinkugbe, hypercholesterolemia defined as total cholesterol (TC) $>5.2 \mathrm{mmol} / \mathrm{L}$ was $4 \%$. This is far less compared to that in Caucasians, and was proposed to be due to environmental, genetic, and dietary factors. ${ }^{10}$ However, recent studies across the country have shown a changing pattern in the occurrence of dyslipidemic hypertension. ${ }^{11-13}$ The prevalence of dyslipidemic hypertension in Nigeria has been reported to be between $45.8 \%$ and $58.9 \%$. The most common single lipid abnormality in these studies is low high-density lipoprotein cholesterol (HDL-C), and in a few cases elevated TC. However, there are also reports of lipid abnormalities occurring in various combinations.

The damaging effect of this unwholesome coexistence of abnormalities is in their atherogenic potential on the endothelium. This results in increased oxidative stress, endothelial dysfunction, and progression of atherosclerosis. ${ }^{14}$ The increasing prevalence of these cardiovascular risk factors places an enormous burden on that already caused by infectious diseases. Hence, screening hypertensive patients at the point of entry cannot be overemphasized. Few studies have determined the pattern and prevalence of lipid abnormalities of individuals with arterial hypertension in North-Central Nigeria and examined the relationship between lipid profile and demographic characteristics. The purpose of this study was therefore to determine the various patterns and the prevalence of lipid profile abnormalities in newly presenting hypertensives in North-Central Nigeria. We also examined the correlation between the serum lipid profiles and demographic characteristics.

\section{Methods}

This cross-sectional study recruited 115 newly presenting hypertensive patients and 115 age- and sex-matched normotensive controls referred to the cardiology clinic of Federal Medical Centre, Bida, between October 2009 and September 2011. Informed and written consent was obtained from the patients; those that declined were excluded from the study. Others excluded include diabetics and patients on antihypertensives and lipid-lowering agents. The normotensive controls were healthy hospital staff, patient relatives, and spouses.

A full medical history was obtained from study participants. Blood pressure was measured in a sitting position using a standard mercury sphygmomanometer after 5 minutes of rest. The average of three consecutive measurements was used for analysis. Hypertension was defined as systolic blood pressure (SBP) $\geq 140 \mathrm{mmHg}$ and/or diastolic blood pressure (DBP) $\geq 90 \mathrm{mmHg}$, using criteria from the Seventh Joint National Committee on detection, evaluation and treatment of hypertension. ${ }^{15}$ Body weight and height were measured with participants wearing light clothes. Body mass index (BMI) was calculated as weight $(\mathrm{kg}) /$ height $(\mathrm{m})^{2}$. Fasting plasma glucose and fasting serum lipid profile were determined using blood obtained following an overnight (10-12 hours) fast. Serum total cholesterol, serum triglycerides (TG), and HDL-C were determined enzymatically. Low-density lipoprotein cholesterol (LDL-C) was determined using the Friedewald formula:

$$
\text { LDL-C }=\text { TC-HDL-C }-(\mathrm{TG} / 5){ }^{16}
$$

The Third Report of the Expert Panel on Detection, Evaluation, and Treatment of High Blood Cholesterol in Adults (ATP III) ${ }^{5}$ was used to define abnormal lipid profiles as follows: elevated $\mathrm{TC}, \geq 5.17 \mathrm{mmol} / \mathrm{L}$; elevated $\mathrm{TG}, \geq 1.69 \mathrm{mmol} / \mathrm{L}$; low HDL-C, $<1.03 \mathrm{mmol} / \mathrm{L}$ for males and $<1.04 \mathrm{mmol} / \mathrm{L}$ for females; and elevated LDL-C, $\geq 3.38 \mathrm{mmol} / \mathrm{L}$. Atherogenic index (AI) was calculated by TC/HDL-C; $>5$ is considered high. ${ }^{17}$ Ethical clearance was obtained from the ethical committee of Federal Medical Centre, Bida.

Data were analyzed using SPSS for Windows version 16.0 software (SPSS Inc, Chicago, IL, USA). Data are reported as mean $\pm \mathrm{SD}$ or as proportions. Comparisons between groups were performed by independent Student's $t$-tests or by chi-square tests. Spearman's correlation and linear regression analysis were used to estimate the association of selected demographic parameters and various parameters of serum lipids. A $P$-value of $<0.05$ was considered statistically significant.

\section{Results}

A total of 230 subjects were involved in the study; 115 were patients with arterial hypertension and 115 were age and sexmatched normotensive controls. Subject ages ranged between 24 and 84 years, with a mean age of $52.90 \pm 12.62$ years and $51.25 \pm 12.21$ years $(P=0.296)$ for hypertensives and controls, respectively. The demographic characteristics of the study population are provided in Table 1 . There were 79 males and 151 females (ratio, 1:1.9). The mean of the BMI, SBP, and DBP are significantly higher in hypertensives $(29.04 \pm 6.87,163.43 \pm 21.17$, and 91.82 \pm 16.64$)$ than the controls $(23.30 \pm 4.23,119.53 \pm 9.86$, and 77.65 $\pm 8.3 ; P=0.000)$. Between hypertensives and controls, the mean serum TC $(4.06 \pm 1.17 ; 3.55 \pm 1.45, P=0.006)$ and serum HDL-C 
Table I Demographic and biochemical parameters of hypertensives and controls

\begin{tabular}{|c|c|c|c|}
\hline Variables & $\begin{array}{l}\text { Hypertensives } \\
(n=|| 5)\end{array}$ & $\begin{array}{l}\text { Controls } \\
(n=\mid 15)\end{array}$ & $P$-value \\
\hline Age (years) & $52.90 \pm 12.62$ & $51.25 \pm \mid 2.21$ & 0.296 \\
\hline Male & $30(26.1)$ & $49(42.6)$ & \\
\hline Female & 85 (73.9) & $66(57.4)$ & 0.080 \\
\hline BMI $\left(\mathrm{kg} / \mathrm{m}^{2}\right)$ & $29.04 \pm 6.87$ & $23.30 \pm 4.23$ & $0.000 *$ \\
\hline SBP (mmHg) & $163.43 \pm 21.17$ & $119.53 \pm 9.86$ & $0.000 *$ \\
\hline $\mathrm{DBP}(\mathrm{mmHg})$ & $91.82 \pm 16.64$ & $77.65 \pm 8.31$ & $0.000 *$ \\
\hline $\mathrm{TC}(\mathrm{mmol} / \mathrm{L})$ & $4.06 \pm 1.17$ & $3.55 \pm 1.45$ & $0.006 *$ \\
\hline $\mathrm{TG}(\mathrm{mmol} / \mathrm{L})$ & $1.31 \pm 0.64$ & $1.23 \pm 0.66$ & 0.431 \\
\hline HDL-C (mmol/L) & $1.16 \pm 0.54$ & $1.44 \pm 0.43$ & $0.000 *$ \\
\hline LDL-C (mmol/L) & $2.4 I \pm 1.10$ & $2.22 \pm 0.94$ & 0.191 \\
\hline $\mathrm{Al}$ & $6.34 \pm 20.28$ & $2.7 I \pm 1.36$ & 0.057 \\
\hline FBS (mmol/L) & $4.55 \pm 2.06$ & $3.98 \pm 4.25$ & 0.36 \\
\hline
\end{tabular}

Note: *Statistically significant.

Abbreviations: Al, atherogenic index; BMI, body mass index; DBP, diastolic blood pressure; FBS, fasting blood sugar; HDL-C, high-density lipoprotein cholesterol; LDL-C, low-density lipoprotein cholesterol; SBP, systolic blood pressure; TC, total cholesterol; TG, triglycerides.

$(1.16 \pm 0.54 ; 1.44 \pm 0.43, P=0.000)$ varied significantly. However, there was no significant difference between the mean serum TG $(1.31 \pm 0.64 ; 1.23 \pm 0.66, P=0.431)$ and the serum LDL-C $(2.41 \pm 1.10 ; 2.22 \pm 0.94, P=0.191)$ among the study population.

\section{Prevalence of dyslipidemia in the hypertensives and controls}

Table 2 shows the prevalence of the various lipid abnormalities as defined by the ATP III diagnostic criteria. In the hypertensive population, 74 participants had at least one form of lipid abnormality, giving a prevalence rate of $64 \%$, and 45 of the controls had at least one lipid abnormality, with a prevalence of $39 \%$. The most common lipid abnormality was reduced HDL-C: $44.3 \%$ in the hypertensive population and $20.9 \%$ in the normotensive controls. None of the participants had all the lipid abnormalities. Many of the hypertensives as well as the controls had more than one lipid abnormality.
Increased TG and low HDL-C (42\%) was the most frequent dyslipidemia combination, followed by increased LDL-C and low HDL-C and increased TC and low HDL-C in equal proportions (9.2\%). Table 3 shows the means of the demographic and laboratory parameters of the hypertensive males and females. Although the male hypertensives were older and had higher SBP and DBP, there was no statistically significant difference between the males and females. There were no other parameter variances between males and females. In a subgroup analysis of hypertensive patients, dyslipidemia occurred most in the age range between 40 and 49 years; thereafter, it plateaued, and subsequently showed a sharp decline from age 70 . This might be explained by the fact that individuals after this age lose subcutaneous fat.

\section{Correlations}

The Spearman's correlation coefficient of serum lipid profiles and some clinical and demographic characteristics of hypertensives and controls are presented in Tables 4 and 5 , respectively. There was a statistically significant correlation between age and LDL-C ( $r=0.217, P=0.020)$, BMI and LDL-C ( $r=0.209, P=0.025)$, and fasting blood sugar and LDL-C $(r=0.202, P=0.030)$ in hypertensives. Also, DBP correlated positively with TC $(r=0.218, P=0.019)$. Among the controls, age and TG were positively correlated $(r=0.196$, $P=0.036)$. A negative correlation was observed between TC and TG ( $r=-0.304, P=0.000)$, whereas TC correlated positively with LDL-C $(r=0.626, P=0.000)$. The AI in hypertensives correlated positively with LDL-C $(r=0.192$, $P=0.006)$, but negatively with HDL-C ( $r=-0.209, P=0.000)$. In controls, the AI showed statistical significance with TC ( $r=0.678, P=0.000)$, but negative correlation with TG $(r=-$ $0.191, P=0.041)$, HDL-C $(r=-0.590, P=0.000)$, and LDL-C $(r=-0.579, P=0.000)$.

The linear regression analysis in hypertensives with HDL-C as a dependent variable and the AI as an independent

Table 2 Prevalence and pattern of lipid abnormalities in hypertensives and controls

\begin{tabular}{lllll}
\hline Variables & Hypertensives (\%) & Controls (\%) & Pearson $\chi^{2}$ & P-value \\
\hline Elevated TC & $13(14.80)$ & $10(8.7)$ & 17.95 & $0.000^{*}$ \\
Elevated TG & $23(20)$ & $16(13.9)$ & 30.39 & $0.000^{*}$ \\
Low HDL-C & $51(44.3)$ & $21(18.3)$ & 41.93 & $0.000^{*}$ \\
Elevated LDL-C & $20(17.4)$ & $9(7.8)$ & 16.01 & $0.000^{*}$ \\
Normal lipid profile & $4 I(35.7)$ & $70(60.87)$ & - & - \\
$\geq$ I abnormality & $74(64.3)$ & $45(39)$ & - & - \\
$\geq 2$ abnormalities & $33(28.7)$ & $7(6.1)$ & - & 16.51 \\
Atherogenic index $>4.5$ & $46(40)$ & $12(10.4)$ & & $0.000^{*}$ \\
\hline
\end{tabular}

Note: *Statistically significant.

Abbreviations: $\chi^{2}$, chi-square test; HDL-C, high-density lipoprotein cholesterol; LDL-C, low-density lipoprotein cholesterol; TC, total cholesterol; TG, triglycerides. 
Table 3 Clinical, demographic, and lipid profile parameters of male and female hypertensives

\begin{tabular}{lccc}
\hline Variables & Males $(\mathbf{n = 1 9 )}$ & Females $(\mathbf{n = 5 5})$ & $P$-value \\
\hline Age $($ years $)$ & $55.26 \pm 10.33$ & $50.13 \pm 13.46$ & $0.09(\mathrm{~ns})$ \\
BMl $\left(\mathrm{kg} / \mathrm{m}^{2}\right)$ & $27.32 \pm 5.80$ & $29.31 \pm 6.85$ & $0.23(\mathrm{~ns})$ \\
SBP $(\mathrm{mmHg})$ & $164.63 \pm 16.69$ & $160.69 \pm 23.63$ & $0.44(\mathrm{~ns})$ \\
DBP $(\mathrm{mmHg})$ & $95.21 \pm 13.59$ & $90.36 \pm 17.10$ & $0.22(\mathrm{~ns})$ \\
TC $(\mathrm{mmol} / \mathrm{L})$ & $3.95 \pm 0.97$ & $4.32 \pm 1.40$ & $0.81(\mathrm{~ns})$ \\
TG $(\mathrm{mmol} / \mathrm{L})$ & $1.40 \pm 0.75$ & $1.47 \pm 0.65$ & $0.75(\mathrm{~ns})$ \\
HDL-C $(\mathrm{mmol} / \mathrm{L})$ & $0.81 \pm 0.6 \mathrm{I}$ & $0.97 \pm 0.40$ & $0.29(\mathrm{~ns})$ \\
LDL-C $(\mathrm{mmol} / \mathrm{L})$ & $2.30 \pm 0.89$ & $2.59 \pm 1.33$ & $0.28(\mathrm{~ns})$ \\
Al & $6.43 \pm 4.10$ & $8.80 \pm 29.09$ & $0.55(\mathrm{~ns})$ \\
\hline
\end{tabular}

Abbreviations: Al, atherogenic index; BMI, body mass index; DBP, diastolic blood pressure; HDL-C, high-density lipoprotein cholesterol; LDL-C, low-density lipoprotein cholesterol; ns, not statistically significant; SBP, systolic blood pressure; TC, total cholesterol; TG, triglycerides.

variable is shown in Table 6. Other variables could not predict HDL-C in the patients or in the controls.

\section{Discussion}

The study was designed to determine the pattern of dyslipidemia and to highlight its relationship with some demographic characteristics of Nigerians presenting with arterial hypertension. Our results have shown that there is a high prevalence of dyslipidemia in newly presenting hypertensives as well as in normotensive controls. Secondly, the prevalence of dyslipidemia increases with age, and is most prevalent

Table 4 Spearman's correlation coefficient for clinical and demographic characteristics and lipid parameters in hypertensives

\begin{tabular}{lllll}
\hline Variables & TC & TG & HDL-C & LDL-C \\
\hline Age (years) & & & & \\
$\quad$ Correlation coefficient & 0.009 & 0.065 & 0.020 & $0.217^{*}$ \\
$\quad$ Significance (2-tailed) & 0.923 & 0.498 & 0.832 & 0.020 \\
BMI (kg/m ${ }^{2}$ ) & & & & \\
$\quad$ Correlation coefficient & 0.126 & 0.124 & -0.038 & $0.209^{*}$ \\
$\quad$ Significance (2-tailed) & 0.181 & 0.186 & 0.686 & 0.025 \\
SBP (mmHg) & & & & \\
$\quad$ Correlation coefficient & 0.021 & -0.113 & -0.066 & 0.053 \\
$\quad$ Significance (2-tailed) & 0.824 & 0.228 & 0.484 & 0.571 \\
DBP (mmHg) & & & & \\
$\quad$ Correlation coefficient & $0.218^{*}$ & -0.071 & 0.017 & -0.094 \\
$\quad$ Significance (2-tailed) & 0.019 & 0.450 & 0.857 & 0.319 \\
FPG (mmol/L) & & & & \\
$\quad$ Correlation coefficient & 0.030 & 0.085 & 0.075 & $0.202^{*}$ \\
$\quad$ Significance (2-tailed) & 0.718 & 0.365 & 0.146 & 0.030 \\
Al $\quad$ & & & \\
$\quad$ Correlation coefficient & 0.086 & 0.147 & $-0.209 *$ & $0.192^{*}$ \\
$\quad$ Significance (2-tailed) & 0.538 & 0.134 & 0.000 & 0.006 \\
\hline
\end{tabular}

Note: *Statistically significant.

Abbreviations: $\mathrm{Al}$, atherogenic index; $\mathrm{BMI}$, body mass index; DBP, diastolic blood pressure; FPG, fasting plasma glucose; HDL-C, high-density lipoprotein cholesterol; LDL-C, low-density lipoprotein cholesterol; SBP, systolic blood pressure; TC, total cholesterol; TG, triglycerides.
Table 5 Spearman's correlation coefficient for clinical and demographic characteristics and lipid parameters in controls

\begin{tabular}{|c|c|c|c|c|}
\hline Variables & TC & TG & HDL-C & LDL-C \\
\hline \multicolumn{5}{|l|}{ Age (years) } \\
\hline Correlation coefficient & -0.165 & $0.196 *$ & 0.066 & 0.155 \\
\hline Significance (2-tailed) & 0.078 & 0.036 & 0.484 & 0.098 \\
\hline \multicolumn{5}{|l|}{ BMI $\left(\mathrm{kg} / \mathrm{m}^{2}\right)$} \\
\hline Correlation coefficient & 0.100 & -0.100 & -0.092 & 0.040 \\
\hline Significance (2-tailed) & 0.289 & 0.289 & 0.653 & 0.670 \\
\hline \multicolumn{5}{|l|}{$\mathrm{SBP}(\mathrm{mmHg})$} \\
\hline Correlation coefficient & 0.089 & 0.060 & 0.008 & 0.141 \\
\hline Significance (2-tailed) & 0.344 & 0.524 & 0.934 & 0.132 \\
\hline \multicolumn{5}{|l|}{$\mathrm{DBP}(\mathrm{mmHg})$} \\
\hline Correlation coefficient & 0.162 & 0.002 & 0.07 I & 0.161 \\
\hline Significance (2-tailed) & 0.084 & 0.907 & 0.450 & 0.850 \\
\hline \multicolumn{5}{|l|}{ FPG (mmol/l) } \\
\hline Correlation coefficient & 0.124 & 0.006 & 0.054 & 0.043 \\
\hline Significance (2-tailed) & 0.456 & $0.34 I$ & 0.642 & 0.812 \\
\hline \multicolumn{5}{|l|}{$\mathrm{Al}$} \\
\hline Correlation coefficient & $0.678^{*}$ & $-0.191 *$ & $-0.590 *$ & $-0.579 *$ \\
\hline Significance (2-tailed) & 0.000 & $0.04 I$ & 0.000 & 0.000 \\
\hline
\end{tabular}

among subjects in the 40-49 age group. Finally, although several combinations of lipid abnormalities were found, the single most common dyslipidemia in our study population was low HDL-C, which is determined by AI.

Much earlier observations by Akinkugbe during the non-communicable diseases study to determine lipid profile abnormalities in Nigerians found a prevalence of $4 \%$ among men and women using the International Diabetes Federation criteria; however, the study did not measure serum HDL-C concentration. ${ }^{10}$ In this study, we measured HDL-C in addition to other parameters, and the rate was found to be much higher. The prevalence rate of $64 \%$ of dyslipidemia in this study is comparable to the $58.9 \%$ reported by Akintunde et a ${ }^{11}$ working on hypertensives in Southwestern Nigeria, but higher than the $40 \%$ reported by Lepira et al. ${ }^{18}$ This might be due to the fact that though Bida is in the North-Central zone, it has seemingly the same climatic conditions as in the earlier study. The inclusion of individuals on lipid-lowering drugs and the level of subject education in the study by Lepira et al might have been responsible for the difference in the prevalence rate. This rate is the same as that found in Caucasians (49.5\% to $78.4 \%$ ), and might be related to the adoption of a Western lifestyle, characterized by physical inactivity and ingestion of foods high in starch and saturated fatty acids. ${ }^{19}$

The finding in this study of significantly different mean values of TC and HDL-C between the hypertensives and the 
Table 6 Linear regression analysis in hypertensives with HDL-C as the dependent variable and Al as the independent variable

\begin{tabular}{|c|c|c|c|c|c|}
\hline HDL-C & $R=0.269$ & $R^{2}=0.072$ & Adjusted & $F$ change $=4.436$ & $P=0.015$ \\
\hline$\overline{\text { Coefficients }}$ & $\beta$ & Standard error & $t$ & Confidence interval (95\%) & Sig \\
\hline$\overline{A l}$ & -0.268 & 0.002 & -0.294 & -0.012 to -0.002 & $0.004 *$ \\
\hline
\end{tabular}

Note: *Statistically significant.

Abbreviations: Al, atherogenic index; HDL-C, high-density lipoprotein cholesterol; Sig, significant.

normotensive controls corroborates previous findings. ${ }^{20,21}$ Although TG and LDL-C were higher in the hypertensives, they did not differ significantly between the hypertensives and the controls, as previously reported. In the hypertensives, TC correlated positively with DBP, but there was no such association in the controls. The higher level of TC in hypertensives which has been noted by other workers may be explained by the association noted with blood pressure in our study. High levels of serum TC have been consistently shown to increase the risk of developing complications like coronary heart disease and stroke in a multiplicative rather than additive manner. The result of an epidemiological study by McGill indicate a progressive increase in cardiovascular risk as the serum TC exceeds $5.0 \mathrm{mmol} / \mathrm{L} .{ }^{22}$ Hence, it is thus generally recommended that treatment of hypertension should, in addition to lowering blood pressure, target correction of dyslipidemia as well as other cardiovascular risk factors if present, to reduce overall risk as well as increasing the cost-effectiveness of therapy.

The single most common individual lipid abnormality in our study subjects was the low HDL-C in $44.3 \%$ of hypertensives and $18.3 \%$ in the normotensive controls. The view has been documented by Akintunde et al, though it appeared twice as often in their controls as in ours. ${ }^{11}$ Osuji et al also found a very high prevalence of low HDL-C in their participants, but a disproportionately higher prevalence in their controls. ${ }^{12}$ Our findings, however, differ from those in Caucasians, where reduced HDL-C is said to be uncommon in the ATP III. ${ }^{5}$ This disparity might be due to the environmental conditions, socioeconomic status, and genetic makeup of our study population, in that isolated low HDL-C may be a relatively common baseline lipid abnormality and hypertension only escalates it. Recently, it has been suggested that, in Caucasians, the apoA-I mutation apoA- $\mathrm{I}_{\text {Nashua }}$ may be responsible for the low HDL-C in Caucasians. ${ }^{23}$ Although the mechanism by which reduced HDL-C increases cardiovascular risk is not fully known, experimental studies suggest a direct role for HDL-C in promoting reverse cholesterol transport from foam cells in the atherosclerotic plaque depots in blood vessels to the liver for excretion. In addition, HDL-C has potent anti-inflammatory and antioxidant effects that inhibit the atherogenic process. ${ }^{24}$ ATP III guidelines recognized low HDL-C as a key determinant of Framingham risk score and a critical factor for ischemic heart disease. ${ }^{5}$

Elevated LDL-C, an atherogenic cholesterol, correlated positively with age, BMI, and fasting blood sugar in our study. In a study by $\mathrm{Xu}$ et al, it was reported that there was a significant upward trend for blood pressure, TC, LDL-C, and TG to increase, whereas HDL-C decreased, with increasing BMI after adjustment for age. ${ }^{9}$ Combined dyslipidemia was also common in our study, with about $28.7 \%$ of the hypertensives having two or more lipid abnormalities. The most frequent abnormality combination was elevated TG and low HDL-C, followed closely by increased LDL-C and low HDL-C. The combined effect of the various lipoproteins might also worsen the cardiovascular risks. Because of this, the ATP III recommends low HDL-C $\leq 1.04 \mathrm{mmol} / \mathrm{L}$ as a secondary target of therapy aimed at lipid lowering to reduce cardiovascular risk.

The main limitation of our study was the fact that it was hospital based; hence, it is difficult to generalize our findings to reflect the whole country. In addition, it was a crosssectional study, and thus cannot be used to predict some of the causal relationships indicated; prospective studies with larger sample sizes are therefore suggested. Finally, we did not measure or calculate other molar ratios of lipids, which may also have confounding effects.

The screening of individuals with arterial hypertension for dyslipidemia is an important step in addressing the everincreasing burden of noncommunicable diseases in Nigeria, a nation that is undergoing epidemiological transition. The present study provides additional information on the various patterns of dyslipidemia and its prevalence in Nigerians with arterial hypertension. The study also supports advocacy on the promotion of healthy lifestyle behaviors and the institution of drugs as appropriate to help reduce the health care burden.

\section{Conclusion}

The prevalence of dyslipidemia in our study population is high and increases with age. The most common dyslipidemia is low HDL-C, and is determined by AI. These findings highlight the need for screening of hypertensives, promotion 
of a healthy lifestyle, and prompt treatment to reduce the multiplicative effect of dyslipidemia combinations.

\section{Acknowledgments}

We express our appreciation to the resident doctors and interns on rotation in the department for their assistance with data collection. This work was presented as an abstract at the 24th Scientific Meeting of the World Congress of Cardiology, April 18-21, 2012, Dubai, United Arab Emirates and earned the presenter the Young Investigators Award.

\section{Disclosure}

The authors report no conflicts of interest in this work.

\section{References}

1. Cooper R, Rotimi C, Ataman S, et al. The prevalence of hypertension in seven populations of west African origin. Am J Public Health. 1997;87(2):160-168.

2. Grundy SM, Hansen B, Smith SC Jr, Cleeman JI, Kahn RA; American Heart Association; National Heart, Lung and Blood Institute; American Diabetes Association. Clinical management of metabolic syndrome: report of the American Heart Association/National Heart, Lung and Blood Institute/American Diabetes Association conference on scientific issues related to management. Arterioscler Thromb Vasc Biol. 2004;24(2):e19-e24.

3. Kannel WB. Fifty years of Framingham Study contributions to understanding hypertension. J Hum Hypertens. 2000;14(2):83-90.

4. Lakka HM, Laaksonen DE, Lakka TA, et al. The metabolic syndrome and total and cardiovascular disease mortality in middle-aged men. JAMA. 2002;288(21):2709-2716.

5. Third Report of the National Cholesterol Education Program (NCEP), Expert panel on detection, evaluation, and treatment of high blood cholesterol in adults (Adult Treatment Panel III) final report. Circulation. 2002;106(25):3143-3421.

6. Tunstall-Pedoe H. What was preventing coronary heart disease (CHD) prevention and why its time has now come. In: Wood D, McLeod A, Davis M, Miles A, editors. Effective Secondary Prevention and Cardiac Rehabilitation. London: Aesculapius Press; 2002:3-13.

7. Eaton CB, Feldman HA, Assaf AR, et al. Prevalence of hypertension, dyslipidemia, and dyslipidemic hypertension. J Fam Pract. 1994;38(1): $17-23$.

8. Schröder H, Schmelz E, Marrugat J. Relationship between diet and blood pressure in a representative Mediterranean population. Eur J Nutr. 2002;41(4):161-167.

9. Xu C, Yang X, Zu S, Han S, Zhang Z, Zhu G. Association between serum lipids, blood pressure, and simple anthropometric measures in an adult Chinese population. Arch Med Res. 2008;39(6):610-617.
10. Akinkugbe OO, editor. Final report of national survey on noncommunicable diseases in Nigeria, series 4. Lagos: Federal Ministry of Health and Human Services. 1997.

11. Akintunde AA, Ayodele EO, Akinwusi OP, Opadijo GO. Dyslipidemia among newly diagnosed hypertensives: pattern and clinical correlates. J Natl Med Assoc. 2010;102(5):403-407.

12. Osuji CU, Omejua EG, Onwubuya EI, Ahaneku GI. Serum lipid profile of newly diagnosed hypertensive patients in nnewi, South-East Nigeria. Int J Hypertens. 2012;2012:710486.

13. Akuyam SA, Aghogho AB, Aliyu IS, Bakari AG. Serum total cholesterol in hypertensive Northern Nigerians. Int J Med Med Sci. 2009; 1(3): $73-78$.

14. Dalal JJ, Padmanabhan TN, Jain P, Patil S, Vasnawala H, Gulati A. LIPITENSION: Interplay between dyslipidemia and hypertension. Indian J Endocrinol Metab. 2012;16(2):240-245.

15. Chobanian AV, Bakris GL, Black HR, et al; and the National High Blood Pressure Education Program Coordinating Committee. Seventh report of the Joint National Committee on Prevention, Detection, Evaluation, and Treatment of High Blood Pressure. Hypertension. 2003;42(6): 1206-1252.

16. Friedewald WT, Levy RI, Fredrickson DS. Estimation of the concentration of low-density lipoprotein cholesterol in plasma, without use of the preparative ultracentrifuge. Clin Chem. 1972;18(6):499-502.

17. Kinosian B, Glick H, Garland G. Cholesterol and coronary heart disease: predicting risks by levels and ratios. Ann Int Med. 1994;121(9): 641-647.

18. Lepira FB, M'Buyamba-Kabangu JR, Kayembe KP, Nseka MN. Correlates of serum lipids and lipoproteins in Congolese patients with arterial hypertension. Cardiovasc J S Afr. 2005;16(5):249-255.

19. O'Meara JG, Kardia SL, Armon JJ, Brown CA, Boerwinkle E, Turner ST. Ethnic and sex differences in the prevalence, treatment, and control of dyslipidemia among hypertensive adults in the GENOA study. Arch Intern Med. 2004;164(12):1313-1318.

20. Oghagbon EK, Okesina AB. Pattern of some risk factors for cardiovascular disease in untreated Nigerian hypertensive patients. West Afr J Med. 2006;25(3):190-194.

21. Ukoh VA, Oforofuo IA. Plasma lipid profiles in Nigerians with normal blood pressure, hypertension and other acquired cardiac conditions. East Afr Med J. 2007;84(6):264-270.

22. McGill HC Jr. Introduction to the geographic pathology of atherosclerosis. Lab Invest. 1968;18(5):465-467.

23. Lee EY, Klementowicz PT, Hegele RA, Asztalos BF, Schaefer EJ. HDL deficiency due to a new insertion mutation (ApoA-INashua) and review of the literature. J Clin Lipidol. 2013;7(2):169-173.

24. Mackness MI, Durrington PN, Mackness B. How high-density lipoprotein protects against the effects of lipid peroxidation. Curr Opin Lipidol. 2000;11(4):383-388.
Vascular Health and Risk Management

\section{Publish your work in this journal}

Vascular Health and Risk Management is an international, peerreviewed journal of therapeutics and risk management, focusing on concise rapid reporting of clinical studies on the processes involved in the maintenance of vascular health; the monitoring, prevention and treatment of vascular disease and its sequelae; and the involvement of

\section{Dovepress}

metabolic disorders, particularly diabetes. This journal is indexed on PubMed Central and MedLine. The manuscript management system is completely online and includes a very quick and fair peer-review system, which is all easy to use. Visit http://www.dovepress.com/ testimonials.php to read real quotes from published authors. 